\title{
Prevalence of Nonclassic Congenital Adrenal Hyperplasia in Turkish Children Presenting with Premature Pubarche, Hirsutism, or Oligomenorrhoea
}

\author{
Cigdem Binay, ${ }^{1}$ Enver Simsek, ${ }^{1}$ Oguz Cilingir, ${ }^{2}$ Zafer Yuksel, ${ }^{2}$ \\ Ozden Kutlay, ${ }^{2}$ and Sevilhan Artan ${ }^{2}$ \\ ${ }^{1}$ Division of Paediatric Endocrinology, Department of Paediatrics, Osmangazi University, School of Medicine, 26480 Eskisehir, Turkey \\ ${ }^{2}$ Department of Medical Genetics, Osmangazi University, School of Medicine, 26480 Eskisehir, Turkey
}

Correspondence should be addressed to Cigdem Binay; cigdembinay@gmail.com

Received 9 December 2013; Revised 17 February 2014; Accepted 18 February 2014; Published 23 March 2014

Academic Editor: Frederic Castinetti

Copyright (c) 2014 Cigdem Binay et al. This is an open access article distributed under the Creative Commons Attribution License, which permits unrestricted use, distribution, and reproduction in any medium, provided the original work is properly cited.

Background. Nonclassic congenital adrenal hyperplasia (NCAH), caused by mutations in the gene encoding 21-hydroxylase, is a common autosomal recessive disorder. In the present work, our aim was to determine the prevalence of NCAH presenting as premature pubarche (PP), hirsutism, or polycystic ovarian syndrome (PCOS) and to evaluate the molecular spectrum of CYP21A2 mutations in NCAH patients. Methods. A total of 126 patients (122 females, 4 males) with PP, hirsutism, or PCOS were included in the present study. All patients underwent an ACTH stimulation test. NCAH was considered to be present when the stimulated 17-hydroxyprogesterone plasma level was $>10 \mathrm{ng} / \mathrm{mL}$. Results. Seventy-one of the 126 patients (56\%) presented with PP, 29 (23\%) with PCOS, and $26(21 \%)$ with hirsutism. Six patients $(4,7 \%)$ were diagnosed with NCAH based on mutational analysis. Four different mutations (Q318X, P30L, V281L, and P453S) were found in six NCAH patients. One patient with NCAH was a compound heterozygote for this mutation, and five were heterozygous. Conclusion. NCAH should be considered as a differential diagnosis in patients presenting with PP, hirsutism, and PCOS, especially in countries in which consanguineous marriages are prevalent.

\section{Introduction}

Nonclassic congenital adrenal hyperplasia $(\mathrm{NCAH})$, caused by 21-hydroxylase deficiency, is one of the most common autosomal recessive disorders in humans, attributable to mutations in the CYP21A2 gene and the related pseudogene CYP21A1P.

Genetic defects in the CYP21A2 gene are classified into three categories depending on the extent of residual enzymatic activity. In vitro studies have shown that mutations causing complete inactivation of 21-hydroxylase activity are associated with the salt-wasting (SW) form of the condition, those that reduce 21 -hydroxylase activity to about $2 \%$ of the normal value with the simple-virilising (SV) form of the disease, and those that reduce 21-hydroxylase activity to 10$75 \%$ of the normal value with the nonclassical (NC) form $[1,2]$.
The prevalence of NCAH varies among ethnic groups, and the condition has been estimated to occur in $0.1 \%$ of the general worldwide population but in 1-2\% of Hispanics and Yugoslavs and 3-4\% of Ashkenazi Jews [3]. Patients with NCAH exhibit variable clinical presentations, but all have signs and symptoms of excess androgen synthesis. Children and adolescents may present with premature pubarche (PP), hirsutism, polycystic ovarian syndrome (PCOS), menstrual dysfunction, severe cystic acne, male-pattern alopecia, advanced bone age, accelerated linear growth velocity, and decreased fertility [4].

$\mathrm{PP}$ is diagnosed based on exclusion of precocious puberty and NCAH. Most children with PP exhibit idiopathic premature adrenal androgen secretion. However, in $5-20 \%$ of such children, PP is caused by NCAH [5]. If it is desired to control the final height attained, early diagnosis is important and treatment should be commenced before signs of 
virilisation become obvious. At adolescence, females are more symptomatic than are males and may present with hirsutism, menstrual irregularity, or PCOS. These symptoms are thought to be caused by androgen excess impairing hypothalamic sensitivity to progesterone and in turn creating persistent GnRH pulsing and LH hypersecretion [4]. The gold standard test for diagnosis of NCAH is assay of stimulated adrenocorticotropic hormone (ACTH) level [6].

In the present study, we evaluated 126 Turkish children and adolescents with suspicious symptoms to determine the prevalence of NCAH. We assayed stimulated ACTH levels in patients presenting with $\mathrm{PP}$, hirsutism, or PCOS and evaluated the molecular pattern of CYP21A2 gene mutations in such patients.

\section{Subjects and Methods}

A total of 126 patients 3-17.8 years of age admitted to our Paediatric Endocrinology Department because of PP, PCOS, or hirsutism were studied. All patients underwent physical examination. Height was measured in the standing position, without shoes, using a stadiometer with a sensitivity of $0.1 \mathrm{~cm}$. Weight was measured using a portable scale (sensitivity, $0.1 \mathrm{~kg}$ ) with the patient dressed in light clothing. Body mass index (BMI) (weight $(\mathrm{kg}) /$ height $(\mathrm{m})^{2}$ ) was recorded. Weight, height, and BMI standard deviations (SD) were calculated using reference curves for Turkish children [7, 8]. Pubertal status was evaluated using the criteria of Marshall and Tanner [9]. Bone-age SD was measured according to Greulich and Pyle [10]. Gender, chronological age, age at symptom onset, birth weight, weight SD, height SD, BMI SD, and bone-age SD were recorded, respectively. Small-for-gestational age (SGA) status was defined as a birth weight below the 10th percentile; children with birth weights between percentiles 10-90 were defined as appropriate-for-gestational age (AGA); and those with birth weights above the 90th percentile were considered to be large-for-gestational age (LGA) [11]. Precocious pubarche was defined as onset of pubic hair growth before the age of 8 years in females and 9 years in males [12]. Prospective subjects were excluded if they exhibited clinical signs of central precocious puberty. PCOS was diagnosed using the criteria of the National Institutes of Health (NIH), thus by clinical and biochemical evidence of hyperandrogenism and ovulatory dysfunction (menstrual irregularity) that could not be explained by the presence of another disorder [13]. The extent of hirsutism was evaluated in nine body areas using a modified Ferriman-Gallwey scoring system, and patients scoring eight or over on the scale were considered to be hirsute [14]. Idiopathic hirsutism was diagnosed in patients with hirsutism who had normal menstrual cycles, normal serum androgen concentrations, and no identifiable cause of hirsutism [15]. All patients underwent ACTH stimulation testing. Female adolescents were tested during the follicular phase of the menstrual cycle. After overnight fasting, $0.25 \mathrm{mg}$ of ACTH (Synachten, Ciba-Geigy, Basel, Switzerland) was injected as an intravenous bolus between 08:00 a.m. and 10:00 a.m.; and cortisol, 17-hydroxyprogesterone (17-OHP), and dehydroepiandrosterone sulphate (DHEAS) levels were measured 0 (basal) and 60 min after ACTH administration.
Cortisol and DHEAS levels were analysed using electrochemiluminescence assays (Roche E-170; Basel, Switzerland). 17-OHP levels were determined by ELISA. NCAH was considered present if the stimulated 17-OHP plasma level was greater than $10 \mathrm{ng} / \mathrm{mL}$. Molecular analysis of the CYP2A2 gene was performed on all patients diagnosed with $\mathrm{NCAH}$ based on the ACTH stimulation test.

\section{Molecular Analysis of CYP21A2}

Peripheral blood samples and genomic DNA from peripheral blood leukocytes were prepared using Roche MagNa Pure Compact Nucleic Acid Isolation Kits and Magna Pure Compact System Kits, respectively (Roche Diagnostics, Indianapolis, IN). Genetic analysis was conducted using a reverse-hybridisation strip-based assay (the CAH StripAssay) that explored the presence of the 11 CYP21A2 mutations most prevalent in European populations: P30L, IVS2 splice (IVS2 G), Del 8bp E3 (G110del8nt), I172N, Cluster E6 (I236N, V237E, and M239K), V281L, L307 frameshift (F306+T), Q318X, R356W, P453S, and R483P.

\section{Statistical Analysis}

SPSS for Windows 20.0 was used for analysis of raw data. The Shapiro-Wilk test was used to confirm that sample data were normally distributed. The parametric Independent Samples $t$-test was used to compare normally distributed data among groups. The nonparametric version of the Mann-Whitney $U$-test was used to perform comparisons among groups exhibiting nonnormal distribution of data. Pearson's chisquared and Fisher's exact tests were used to conduct paired categorical data analysis. All data are expressed as means \pm SD or median values obtained at percentiles 25 and 75 (Q1 and Q3). A $P$ value $<0.05$ was considered to reflect statistical significance.

\section{Results}

Seventy-one of the 126 patients (56\%) presented with PP, $29(23 \%)$ with PCOS, and 26 (21\%) with hirsutism. Mean age at symptom onset was $6.6 \pm 1.2$ years in PP patients, $12.6 \pm 1.3$ years in PCOS patients, and $11.5 \pm 2.8$ years in patients with hirsutism. Birth weight data were available for 108 patients; 18 children scored as SGA, four as LGA, and 86 as AGA. Ferriman-Gallway scores were available only for PCOS patients (mean: $19.7 \pm 5$ ) or those with hirsutism (mean: $20.6 \pm 4$ ). Clinical and biochemical data on all study subjects are shown in Table 1. Examination of 17-OHP values after ACTH stimulation revealed that nine patients (7.1\%) had NCAH. Based on the genetic analysis, six patients (4.7\%) were diagnosed with NCAH. The NCAH prevalence was 4.2\% $(n=3)$ in PP patients, $6.8 \%(n=2)$ in PCOS patients, and $3.8 \%(n=1)$ in patients with hirsutism.

The clinical characteristics of and laboratory findings of all patients with or without NCAH are shown in Table 1. Basal and stimulated levels of 17-OHP and bone-age SD were significantly higher in those with than without NCAH $(P<$ 0.05 for all comparisons). 
TABLE 1: Clinical characteristics and laboratory findings of study subjects.

\begin{tabular}{lccc}
\hline & Subjects without NCAH & Subjects with NCAH & $P$ value \\
\hline Age $($ year $)$ & $8,80(7,30-14,60)$ & $7,80(6,80-13,30)$ & 0,336 \\
Gender $($ female/male) & $113 / 4$ & $9 / 0$ & 0,741 \\
BMI SDS & $0,82 \pm 0,09$ & $1,03 \pm 0,36$ & 0,572 \\
Height SDS & $0,33 \pm 1,10$ & $0,49 \pm 0,39$ & 0,685 \\
Bone Age SDS & $1,02 \pm 0,09$ & $2,07 \pm 0,12$ & $\mathbf{0 , 0 0 2}$ \\
Ferriman Gallway Score & $20,18 \pm 4,65$ & $23,00 \pm 5,00$ & 0,594 \\
T.Testosterone $(\mathrm{ng} / \mathrm{dL})$ & $16,50(0,69-38,37)$ & $7,05(0,79-20)$ & 0,752 \\
Cortisol $_{0}(\mu \mathrm{g} / \mathrm{dL})$ & $14,41 \pm 5,72$ & $13,75 \pm 5,68$ & 0,740 \\
Cortisol $_{1 \text { hour }}(\mu \mathrm{g} / \mathrm{dL})$ & $28,69 \pm 5,66$ & $32,47 \pm 5,30$ & 0,055 \\
17-OHP $_{0}(\mathrm{ng} / \mathrm{mL})$ & $1,20(0,90-2)$ & $3,90(2,15-9,50)$ & $<\mathbf{0 , 0 0 1}$ \\
17-OHP $_{1 \text { hour }}(\mathrm{ng} / \mathrm{mL})$ & $3,10(2,25-4,40)$ & $21,60(9,80-34,05)$ & $<\mathbf{0 , 0 0 1}$ \\
DHEA-S $_{0}(\mu \mathrm{g} / \mathrm{dL})$ & $103(53,50-181,50)$ & $128(128-331,50)$ & 0,619 \\
DHEA-S $_{1 \text { hour }}(\mu \mathrm{g} / \mathrm{dL})$ & $102(53,70-188,50)$ & $130(50,50-312,50)$ & 0,622 \\
\hline
\end{tabular}

Data are expressed as the means \pm standard deviations or medians (Q1-Q3) as appropriate. NCAH: nonclassic congenital adrenal hyperplasia; BMI-SDS: body mass index standard deviation score; 17-OHP: 17-hydroxyprogesterone; DHEA-S: dehydroepiandrosterone sulphate.

TABLE 2: Comparisons of clinical and laboratory findings between patients with nonclassic congenital adrenal hyperplasia and premature pubarche.

\begin{tabular}{lccc}
\hline & IPP $(n=65)$ & NCAH $(n=6)$ & $P$ value \\
\hline Gender (female/male) & $61 / 4$ & $6 / 0$ & 0,697 \\
Age $($ year $)$ & $7,50(6,95-8,20)$ & $6,90(6,60-8,85)$ & 0,400 \\
BMI SDS & $0,85 \pm 0,99$ & $0,94 \pm 1,17$ & 0,827 \\
Height SDS & $0,71 \pm 1,11$ & $0,91 \pm 1,15$ & 0,676 \\
Bone Age SDS & $1,12 \pm 1,02$ & $2,11 \pm 0,43$ & $\mathbf{0 , 0 2 2}$ \\
T.Testosterone $(\mathrm{ng} / \mathrm{dL})_{\text {Cortisol }_{0 \text { hour }}(\mu \mathrm{g} / \mathrm{dL})}^{9,47(0,30-20)}$ & $20(4,82-45,50)$ & 0,258 \\
Cortisol $_{1 \text { hour }}(\mu \mathrm{g} / \mathrm{dL})$ & $13 \pm 5,36$ & $11,86 \pm 3,14$ & 0,594 \\
17-OHP $_{0 \text { hour }}(\mathrm{ng} / \mathrm{mL})$ & $29,20(24,30-32,20)$ & $31,70(29-35)$ & 0,121 \\
17-OHP $_{1 \text { hour }}(\mathrm{ng} / \mathrm{mL})$ & $1,18 \pm 1,01$ & $6,33 \pm 4,96$ & 0,052 \\
DHEA-S $_{0 \text { hour }}(\mu \mathrm{g} / \mathrm{dL})$ & $3(2,20-4)$ & $25,30(9,97-39,32)$ & $<\mathbf{0 , 0 0 1}$ \\
DHEA-S $_{1 \text { hour }}(\mu \mathrm{g} / \mathrm{dL})$ & $65,20(43,70-107)$ & $62,40(40,77-128,50)$ & 0,960 \\
\hline
\end{tabular}

Data are expressed as means \pm standard deviations or medians (Q1-Q3) as appropriate. IPP: idiopathic premature pubarche; NCAH: nonclassic congenital adrenal hyperplasia; BMI SDS: body mass index standard deviation score; 17-OHP: 17-hydroxyprogesterone; DHEA-S: dehydroepiandrosterone sulphate.

Data on patients with or without NCAH were compared with those of PP patients. Nonpathological exaggerated secretion of androgen was defined as idiopathic PP (IPP). The clinical characteristics of and laboratory findings on IPP and NCAH patients are shown in Table 2. The stimulated levels of 17-OHP, and bone-age SD, were higher in children with NCAH $(P<0.05)$. However, no significant difference in any of chronological age, BMI SD, height SD, baseline or stimulated cortisol level, or baseline 17-OHP or DHEAS level was evident between children with PP and NCAH. Birth weight data were available for 60 patients; 13 children were of SGA status, two of LGA, and 45 of AGA. Birth weight did not differ between patients diagnosed with or without NCAH $(P>0.05)$.

The clinical characteristics of nine patients diagnosed with NCAH according to the ACTH stimulation test are shown in Table 3. Six of these patients presented with PP, two with PCOS, and one with hirsutism. Four different mutations (Q318X, P30L, V281L, and P453S) were found in six of the nine patients diagnosed with NCAH. One patient with PP had compound heterozygous mutations (V281L and P30L). Five patients were heterozygous for disease-related mutations. V281L and P453S mutations were detected in PP patients, P30L was detected in PCOS patients, and Q318X in patients with both PCOS and hirsutism. Consanguinity was in play in three of nine $\mathrm{NCAH}$ patients.

\section{Discussion}

Nonclassic congenital adrenal hyperplasia should be considered in the differential diagnosis of PP, PCOS, and IH, because neither clinical presentation nor androgen level is a reliable predictor of this disease. In the present study, we determined the prevalence of NCAH in children and adolescents presenting with symptoms of androgen excess and evaluated the clinical characteristics of such patients. 
TABLE 3: Clinical characteristics and genotypes of patients with nonclassic congenital adrenal hyperplasia.

\begin{tabular}{lcccccccc}
\hline Patient & Genotype & Clinical feature & Age & Gender & Consanguinity & BA-SDS & $17-$ OHP $_{0}$ & $1_{-O H P}$ peak \\
\hline 1 & NA & PP & 6,8 & F & No & $+1,5$ & 13 & 40 \\
2 & V281L/P30L & PP & 6,0 & F & No & $+2,6$ & 2,1 & 10 \\
3 & NA & PP & 7,8 & F & No & $+1,7$ & 10,6 & 39 \\
4 & NA & PP & 6,8 & F & No & $+2,4$ & 8,4 & 21,6 \\
5 & Q318X & Hirsutism & 13,1 & F & Yes & $+2,3$ & 2,3 & 10,5 \\
6 & Q318X & PCOS & 13,5 & F & No & $+2,0$ & 3,9 & 10,8 \\
7 & P30L & PCOS & 15,9 & F & Yes & $+1,7$ & 8,1 & 26,5 \\
8 & V281L & PP & 7,0 & F & Yes & $+2,4$ & 2,2 \\
9 & P453S & PP & 12,0 & F & No & $+2,1$ & 29 \\
\hline
\end{tabular}

NA: not applicable; BA-SDS: bone age-standard deviation score; 17-OHP: 17-hydroxyprogesterone; PP: premature pubarche; PCOS: polycystic ovarian syndrome.

The prevalence of NCAH in children with PP varies between 0 and $40 \%$ among different populations [16-19], and the prevalence of NCAH causing hirsutism or PCOS is up to $20 \%$, varying with both ethnicity and geographical area [20-22]. Few data have been gathered on the prevalence of NCAH in Turkish PP patients. Erdeve et al. [23] studied 159 patients, and Gonc et al. [24] reported 186 patients; the prevalences of non-classical CAH were $5.7 \%$ and $3.2 \%$, respectively. In our cohort, six patients (4.7\%) were diagnosed with NCAH based on the genetic analysis. The prevalence of NCAH was $4.2 \%(n=3)$ in PP patients, $6.8 \%(n=2)$ in PCOS patients, and $3.8 \%(n=1)$ in patients with hirsutism. Unluhizarci et al. [25] conducted an extensive study of hirsute and hyperandrogenic females from various regions of Turkey. The cited authors concluded that NCAH was not prevalent in the Turkish population (the incidence was 2.1\%) [25]. Akinci et al. [26] found that the prevalence of $\mathrm{NCAH}$ in hirsute adolescent females was 3.1\%, and Yarman et al. [27] found an NCAH prevalence of $33 \%$ in Turkish females with hirsutism and PCOS; the data were confirmed by genotyping and HLA typing. The high prevalence noted in the cited report was considered to be associated with ethnic diversity in Istanbul. In another Turkish study, the prevalence of NCAH was $6.9 \%$ in Turkish woman with PCOS and 15\% in those with IH [28].

The limitations of the present study include the small number of patients (three) diagnosed with NCAH causing hirsutism or PCOS; we were unable to compare adolescents with hirsutism to those with PCOS and NCAH. However, we have described the clinical and laboratory findings of patients exhibiting androgen excess and we compared data on all patients with those of nine patients with NCAH. We examined all IPP patients, and the six patients for whom NCAH was diagnosed as the cause of PP, in an effort to identify factors predictive of NCAH development. Most prior studies have proposed that patients with NCAH exhibit accelerated bone-age maturation [23, 29-31] and increased basal or stimulated levels of 17-OHP [29, 32, 33]. In the present study, as expected, the basal and stimulated levels of 17-OHP were higher $(P<0.001)$, and the bone-age SD was more advanced $(P<0.05)$, in children with NCAH. However, we found no between-group difference in any of current age, age at onset of symptoms, BMI, height, baseline and stimulated levels of cortisol, or DHEAS ( $P>0.05$ for all comparisons). Birth weight did not differ between patients diagnosed with or without NCAH $(P>0.05)$. Similarly, neither birth weight nor testosterone level was a predictor of NCAH development in the study of von Oettingen et al. [29], which involved 122 patients of varied ethnicity presenting with premature adrenarche. This result is in contrast with previous reports that elevated basal testosterone is a potential predictor of NCAH development $[5,33]$. Ghizzoni et al. [34] studied the clinical and biochemical profiles of 152 Italian children with PP and genotypically screened all subjects. The cited authors could not define any diagnostic clinical characteristic of NCAH patients; even bone-age was not informative. Similarly, Ibáñez et al. [17] were unable to identify any clinical parameter differentiating PP patients into those with or without NCAH.

In our patient cohort, two of 29 PCOS patients and one of 26 patients with hirsutism were diagnosed with NCAH. Adolescent females with NCAH may suffer from gonadal dysfunction, menstrual disorders, or PCOS. These conditions are thought to be caused by conversion of adrenal androgens to oestrogens, altering the level of gonadotropin secretion or disrupting the cyclicity of gonadotropin release, thus directly affecting the ovary and ultimately leading to formation of androgen-producing cysts. Many authors have examined the similarity between NCAH and PCOS and the differences that might differentiate these two diseases. Obesity, insulin resistance, hirsutism, and polycystic ovarian morphology may be present in both NCAH and PCOS. The only exception is that the 17-OHP level is not elevated significantly in PCOS, at least not to the levels seen in NCAH. It has been suggested that NCAH should be excluded in patients presenting with hirsutism, oligomenorrhoea, and polycystic ovarian morphology. Alternations in CYP21A2 gene transcription should be kept in mind as a cause of PCOS $[22,28,35]$.

Molecular analyses of the CYP21A2 gene were performed on nine patients diagnosed with NCAH according to the ACTH stimulation test. The V281L and P453S mutations were detected in PP patients; P30L was detected in PCOS patients; and Q318X was detected in patients with either or both of PCOS and hirsutism. Consanguinity was in play in three patients. Two PP patients in the V281L-heterozygous 
group had bone-age $\mathrm{SD} \geq 2$, and the basal levels of $17-\mathrm{OHP}$ were 2.1 and $2.2 \mathrm{ng} / \mathrm{mL}$, respectively. Consanguinity was in play in one patient. Both patients presented with hirsutism and PCOS were heterozygous for Q318X and had boneage SD and peak 17-OHP levels of +2.3 and $10.8 \mathrm{ng} / \mathrm{mL}$, respectively. The bone-age SD was $<2$ in a PCOS patient in whom P30L heterozygosity was recorded. In patients with relevant mutations, the maximum stimulated 17-OHP level was $29 \mathrm{ng} / \mathrm{mL}$. It is surprising that the basal and peak levels of 17-OHP were higher in patients in whom we did not detect any mutation. This may indicate that it is important to evaluate other regions of the CYP21A2 gene to detect rare mutations causing disease.

Previous studies have shown that mutations exerting mild phenotypic effects (the V281L, P30L, and P453S mutations) result in retention of $20-50 \%$ of enzymatic activity, and mutations exerting severe phenotypic effects (I2 splice, I172N, and Q318X) $0-2 \%[3,36-38]$. An association is evident between genotype and phenotype. Homozygous mutations exerting mild phenotypic effects and heterozygous mutations with mild or severe phenotypic effects trigger the nonclassical form of the disease [38]. Our results are consistent with these earlier data.

The phenotypic heterogeneity of NCAH patients can be explained by the simultaneous expression of different mutations. Such patients may carry an unidentified mutation in the other CYP21A2 allele or may carry a mutation exerting a mild phenotypic effect in one allele only [3]. This suggests that patients who are compound heterozygotes for one mutation exerting a mild phenotypic effect and another exerting a severe phenotypic effect may be younger have a greater height SD, exhibit a more advanced bone age, and express a higher $17-\mathrm{OHP}$ level at presentation $[2,36]$. However, in the absence of full sequences of the CYP21 gene and regulatory elements thereof, we cannot presently draw such conclusions. The V281L mutation was more common than the P30L mutation in NCAH patients presenting with PCOS and hirsutism [21, 39, 40]. As found previously, the Q318X mutation was also noted in patients presenting with PCOS [22, 41]. Erdeve et al. [23] detected the V281L mutation in all PP patients of a Turkish population and suggested that the condition was caused by this mutation rather than other known mutations. Moreover, it has been reported that the V281L mutation is the most common mutation in Turkish patients with PP, PCOS, and hirsutism [25, 27]. In the present study, the Q318X, $\mathrm{P} 30 \mathrm{~L}$, and $\mathrm{P} 453 \mathrm{~S}$ mutations were detected, in addition to the V281L mutation, in four patients presenting with PP, PCOS, or hirsutism. The P453S mutation was previously noted in Turkish children with NCAH $[42,43]$. In other countries, the P453S and P30L mutations were found in $23.1 \%$ and $10.3 \%$, respectively, of NCAH patients [3]. Helmberg et al. [38] identified $\mathrm{R} 339 \mathrm{H}$ and $\mathrm{P} 453 \mathrm{~S}$ mutations associated with NCAH and proposed that each mutation caused a $50 \%$ reduction in normal CYP21A2 activity. In another study, P453S was found in $46.2 \%$ of NCAH patients [44].

In conclusion, $\mathrm{NCAH}$ is a heterogeneous disorder in terms of age of onset, symptomology, and causative mutation. NCAH should be a differential diagnosis in patients presenting with PP, hirsutism, PCOS, and/or advanced bone age, especially in countries in which consanguineous marriages are prevalent. Investigating the molecular genetic mechanism of NCAH should resolve the diagnostic difficulties encountered with hormone testing. Genotyping should be considered for defining biological cohorts and it should shed light on whether the genetic variation is related to the disease in question. Of our nine NCAH patients, five had heterozygous and one had compound heterozygous mutations. Other disease-related mutations may also be present in such patients. Therefore, sequencing is the gold standard for identification of disease-associated mutations.

\section{Conflict of Interests}

The authors declare that there is no conflict of interests regarding the publication of this paper.

\section{References}

[1] P. W. Speiser, J. Dupont, D. Zhu et al., "Disease expression and molecular genotype in congenital adrenal hyperplasia due to 21hydroxylase deficiency," Journal of Clinical Investigation, vol. 90, no. 2, pp. 584-595, 1992.

[2] P. W. Speiser, E. S. Knochenhauer, D. Dewailly, F. Fruzzetti, J. A. M. Marcondes, and R. Azziz, "A multicenter study of women with nonclassical congenital adrenal hyperplasia: relationship between genotype and phenotype," Molecular Genetics and Metabolism, vol. 71, no. 3, pp. 527-534, 2000.

[3] P. C. White and P. W. Speiser, "Congenital adrenal hyperplasia due to 21-hydroxylase deficiency," Endocrine Reviews, vol. 21, no. 3, pp. 245-291, 2000.

[4] S. F. Witchel and R. Azziz, "Nonclassic congenital adrenal hyperplasia," International Journal of Pediatric Endocrinology, vol. 2010, Article ID 625105, 2010.

[5] J.-B. Armengaud, M.-L. Charkaluk, C. Trivin et al., "Precocious pubarche: distinguishing late-onset congenital adrenal hyperplasia from premature adrenarche," Journal of Clinical Endocrinology and Metabolism, vol. 94, no. 8, pp. 2835-2840, 2009.

[6] P. W. Speiser, "Nonclassic adrenal hyperplasia," Reviews in Endocrine and Metabolic Disorders, vol. 10, no. 1, pp. 77-82, 2009.

[7] O. Neyzi, A. Furman, R. Bundak, H. Gunoz, F. Darendeliler, and F. Bas, "Growth references for Turkish children aged 6 to 18 years," Acta Paediatrica, vol. 95, no. 12, pp. 1635-1641, 2006.

[8] R. Bundak, A. Furman, H. Gunoz, F. Darendeliler, F. Bas, and O. Neyzi, “Body mass index references for Turkish children," Acta Paediatrica, vol. 95, no. 2, pp. 194-198, 2006.

[9] W. A. Marshall and J. M. Tanner, "Variations in pattern of pubertal changes in girls," Archives of Disease in Childhood, vol. 44, no. 235, pp. 291-303, 1969.

[10] W. W. Greulich and S. I. Pyle, Radiographic Atlas of Skeletal Development of the Hand and Wrist, Stanford University Press, Stanford, Calif, USA, 1966.

[11] F. C. Battaglia and L. O. Lubchenco, "A practical classification of newborn infants by weight and gestational age," The Journal of Pediatrics, vol. 71, no. 2, pp. 159-163, 1967.

[12] L. Ibanez, N. Potau, D. Dunger, and F. De Zegher, "Precocious pubarche in girls and the development of androgen excess," Journal of Pediatric Endocrinology and Metabolism, vol. 13, no. 5, pp. 1261-1263, 2000. 
[13] J. Zawadzki and A. Dunaif, "Diagnostic criteria for polycystic ovary syndrome: towards a rational approach," in Polycystic Ovary Syndrome, A. Dunaif, J. Givens, F. Haseltine et al., Eds., p. 377, Blackwell Scientific Publications, Cambridge, Mass, USA, 1992.

[14] R. Hatch, R. L. Rosenfield, M. H. Kim, and D. Tredway, "Hirsutism: implications, etiology, and management," American Journal of Obstetrics and Gynecology, vol. 140, no. 7, pp. 815-830, 1981.

[15] R. Azziz, E. Carmina, and M. E. Sawaya, "Idiopathic hirsutism," Endocrine Reviews, vol. 21, no. 4, pp. 347-362, 2000.

[16] V. O. Moura-Massari, D. D. Bugano, J. A. Marcondes, L. G. Gomes, B. B. Mendonca, and T. A. Bachega, "CYP21A2 genotypes do not predict the severity of hyperandrogenic manifestations in the nonclassical form of congenital adrenal hyperplasia," Hormone and Metabolic Research, vol. 45, no. 4, pp. 301-307, 2013.

[17] L. Ibáñez, M. R. Bonnin, M. Zampolli, N. Prat, P. J. Alia, and M. A. Navarro, "Usefulness of an ACTH test in the diagnosis of nonclassical 21-hydroxylase deficiency among children presenting with premature pubarche," Hormone Research, vol. 44, no. 2, pp. 51-56, 1995.

[18] A. H. Morris, E. O. Reiter, M. E. Geffner, B. M. Lippe, R. M. Itami, and D. M. Mayes, "Absence of nonclassical congenital adrenal hyperplasia in patients with precocious adrenarche," Journal of Clinical Endocrinology and Metabolism, vol. 69, no. 4, pp. 709-715, 1989.

[19] D. Knorr, F. Bidlingmaier, and W. Holler, "Is heterozygosity for the steroid 21-hydroxylase deficiency responsible for hirsutism, premature pubarche, early puberty, and precocious puberty in children?" Acta Endocrinologica, vol. 113, no. 279, pp. 284-289, 1986.

[20] H. F. Escobar-Morreale, R. Sanchón, and J. L. San Millán, “A prospective study of the prevalence of nonclassical congenital adrenal hyperplasia among women presenting with hyperandrogenic symptoms and signs," Journal of Clinical Endocrinology and Metabolism, vol. 93, no. 2, pp. 527-533, 2008.

[21] M. Fanta, D. Cibula, and J. Vrbíková, "Prevalence of nonclassic adrenal hyperplasia (NCAH) in hyperandrogenic women," Gynecological Endocrinology, vol. 24, no. 3, pp. 154-157, 2008.

[22] M. Pall, R. Azziz, J. Beires, and D. Pignatelli, “The phenotype of hirsute women: a comparison of polycystic ovary syndrome and 21-hydroxylase-deficient nonclassic adrenal hyperplasia," Fertility and Sterility, vol. 94, no. 2, pp. 684-689, 2010.

[23] S. S. Erdeve, M. Berberoglu, N. Yurur-Kutlay et al., "Characteristics and prevalence of non-classical congenital adrenal hyperplasia with a V281l mutation in patients with premature pubarche," Journal of Pediatric Endocrinology and Metabolism, vol. 24, no. 11-12, pp. 965-970, 2011.

[24] E. N. Gonc, Z. A. Ozon, A. Alikasifoglu, O. Engiz, B. Bulum, and N. Kandemir, "Is basal serum 17-OH progesterone reliable parameter to predict nonclassical congenital adrenal hyperplasia in premature adrenarche?" Turkish Journal of Pediatrics, vol. 53, no. 3, pp. 274-280, 2011.

[25] K. Unluhizarci, M. Kula, M. Dundar et al., "The prevalence of non-classic adrenal hyperplasia among Turkish women with hyperandrogenism," Gynecological Endocrinology, vol. 26, no. 2, pp. 139-143, 2010.

[26] A. Akinci, N. Yordam, F. Ersoy, N. Ulusahin, and H. Oguz, "The incidence of non-classical 21 -hydroxylase deficiency in hirsute adolescent girls," Gynecological Endocrinology, vol. 6, no. 2, pp. 99-106, 1992.
[27] S. Yarman, A. Dursun, F. Oguz, and F. Alagöl, "The prevalence, molecular analysis and HLA typing of late-onset 21-hydroxylase deficiency in Turkish woman with hirsutism and polycystic ovary," Endocrine Journal, vol. 51, no. 1, pp. 31-36, 2004.

[28] N. Kamel, V. Tonyukuk, R. Emral, D. Çorapçioğlu, M. Baştemir, and S. Güllü, "The prevalence of late onset congenital adrenal hyperplasia in hirsute women from Central Anatolia," Endocrine Journal, vol. 50, no. 6, pp. 815-823, 2003.

[29] J. von Oettingen, J. Sola Pou, L. L. Levitsky, and M. Misra, "Clinical presentation of children with premature adrenarche," Clinical Pediatrics, vol. 51, no. 2, pp. 1140-1149, 2012.

[30] C. Dacou-Voutetakis and M. Dracopoulou, "High incidence of molecular defects of the CYP21 gene in patients with premature adrenarche," Journal of Clinical Endocrinology and Metabolism, vol. 84, no. 5, pp. 1570-1574, 1999.

[31] S. F. Siegel, D. N. Finegold, M. D. Urban, R. McVie, and P. A. Lee, "Premature pubarche: etiological heterogeneity," Journal of Clinical Endocrinology and Metabolism, vol. 74, no. 2, pp. 239247, 1992.

[32] S. G. Accetta, K. di Domênico, C. G. Ritter, A. T. Ritter, E. Capp, and P. M. Spritzer, "Anthropometric and endocrine features in girls with isolated premature pubarche or nonclassical congenital adrenal hyperplasia," Journal of Pediatric Endocrinology and Metabolism, vol. 17, no. 5, pp. 767-773, 2004.

[33] F. Paris, V. Tardy, A. Chalançon, M. C. Picot, Y. Morel, and C. Sultan, "Premature pubarche in Mediterranean girls: high prevalence of heterozygous CYP21 mutation carriers," Gynecological Endocrinology, vol. 26, no. 5, pp. 319-324, 2010.

[34] L. Ghizzoni, M. Cappa, A. Vottero et al., "Relationship of CYP21A2 genotype and serum 17-hydroxyprogesterone and cortisol levels in a large cohort of Italian children with premature pubarche," European Journal of Endocrinology, vol. 165, no. 2, pp. 307-314, 2011.

[35] D. Pignatelli, "Non-classic adrenal hyperplasia due to the deficiency of 21-hydroxylase and its relation to polycystic ovarian syndrome," Frontiers of Hormone Research, vol. 40, pp. 158-170, 2013.

[36] M.-T. Tusie-Luna, P. Traktman, and P. C. White, "Determination of functional effects of mutations in the steroid 21-hydroxylase gene (CYP21) using recombinant vaccinia virus," Journal of Biological Chemistry, vol. 265, no. 34, pp. 20916-20922, 1990.

[37] P. W. Speiser and P. C. White, "Congenital adrenal hyperplasia due to steroid 21-hydroxylase deficiency," Clinical Endocrinology, vol. 49, no. 4, pp. 411-417, 1998.

[38] A. Helmberg, M.-T. Tusie-Luna, M. Tabarelli, R. Kofler, and P. C. White, "R339H and P453S: CYP21 mutations associated with nonclassic steroid 21- hydroxylase deficiency that are not apparent gene conversions," Molecular Endocrinology, vol. 6, no. 8, pp. 1318-1322, 1992.

[39] G. Rumsby, C. J. Avey, G. S. Conway, and J. W. Honour, "Genotype-phenotype analysis in late onset 21-hydroxylase deficiency in comparison to the classical forms," Clinical Endocrinology, vol. 48, no. 6, pp. 707-711, 1998.

[40] N. Skordis, C. Shammas, E. Efstathiou, K. Kaffe, V. Neocleous, and L. A. Phylactou, "Endocrine profile and phenotypegenotype correlation in unrelated patients with non-classical congenital adrenal hyperplasia," Clinical Biochemistry, vol. 44, no. 12, pp. 959-963, 2011.

[41] M.-T. Tusie-Luna, P. W. Speiser, M. Dumic, M. I. New, and P. C. White, "A mutation (Pro-30 to Leu) in CYP21 represents a potential nonclassic steroid 21-hydroxylase deficiency allele," Molecular Endocrinology, vol. 5, no. 5, pp. 685-692, 1991. 
[42] T. Tukel, O. Uyguner, J. Q. Wei et al., "A novel semiquantitative polymerase chain reaction/enzyme digestion-based method for detection of large scale deletions/conversions of the CYP21 gene and mutation screening in Turkish families with 21-hydroxylase deficiency," Journal of Clinical Endocrinology and Metabolism, vol. 88, no. 12, pp. 5893-5897, 2003.

[43] F. Baş, H. Kayserili, F. Darendeliler et al., "CYP21A2 gene mutations in congenital adrenal hyperplasia: genotype-phenotype correlation in Turkish children," Journal of Clinical Research in Pediatric Endocrinology, vol. 1, no. 3, pp. 116-128, 2009.

[44] D. Owerbach, L. Sherman, A.-L. Ballard, and R. Azziz, "Pro-453 to Ser mutation in CYP21 is associated with nonclassic steroid 21-hydroxylase deficiency," Molecular Endocrinology, vol. 6, no. 8, pp. 1211-1215, 1992. 


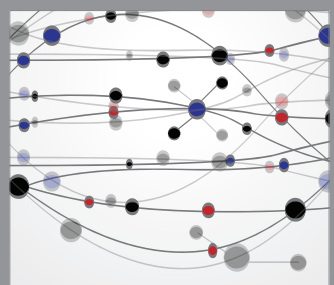

The Scientific World Journal
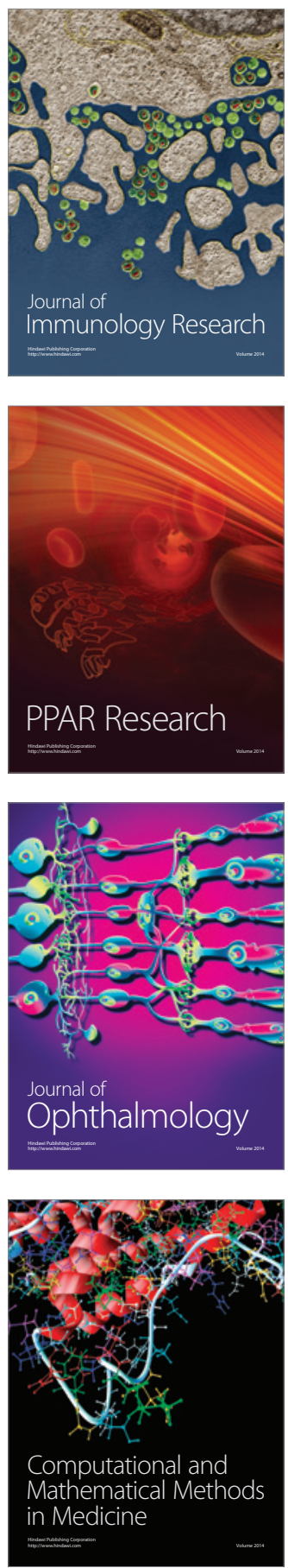

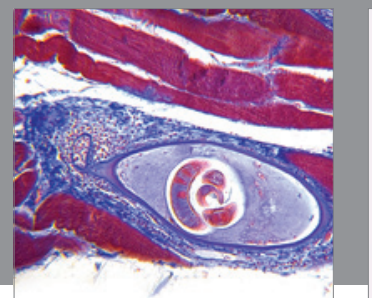

Gastroenterology

Research and Practice
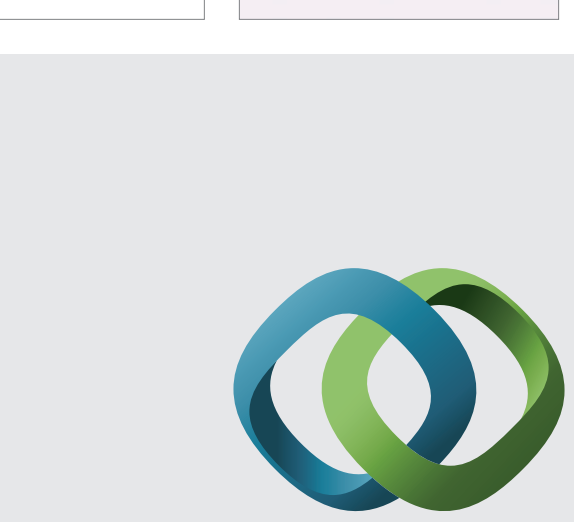

\section{Hindawi}

Submit your manuscripts at

http://www.hindawi.com
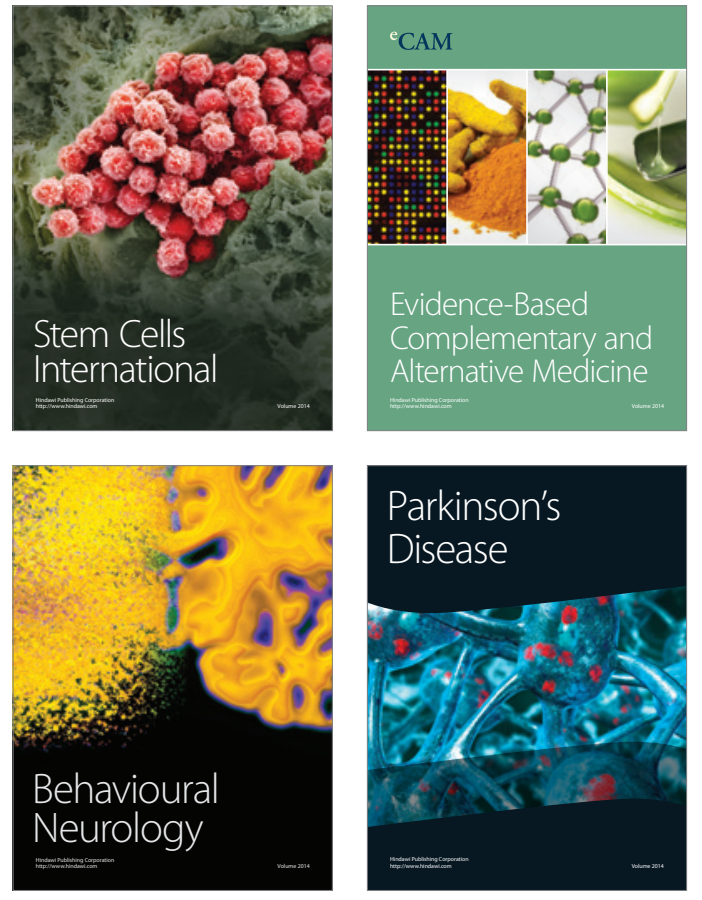
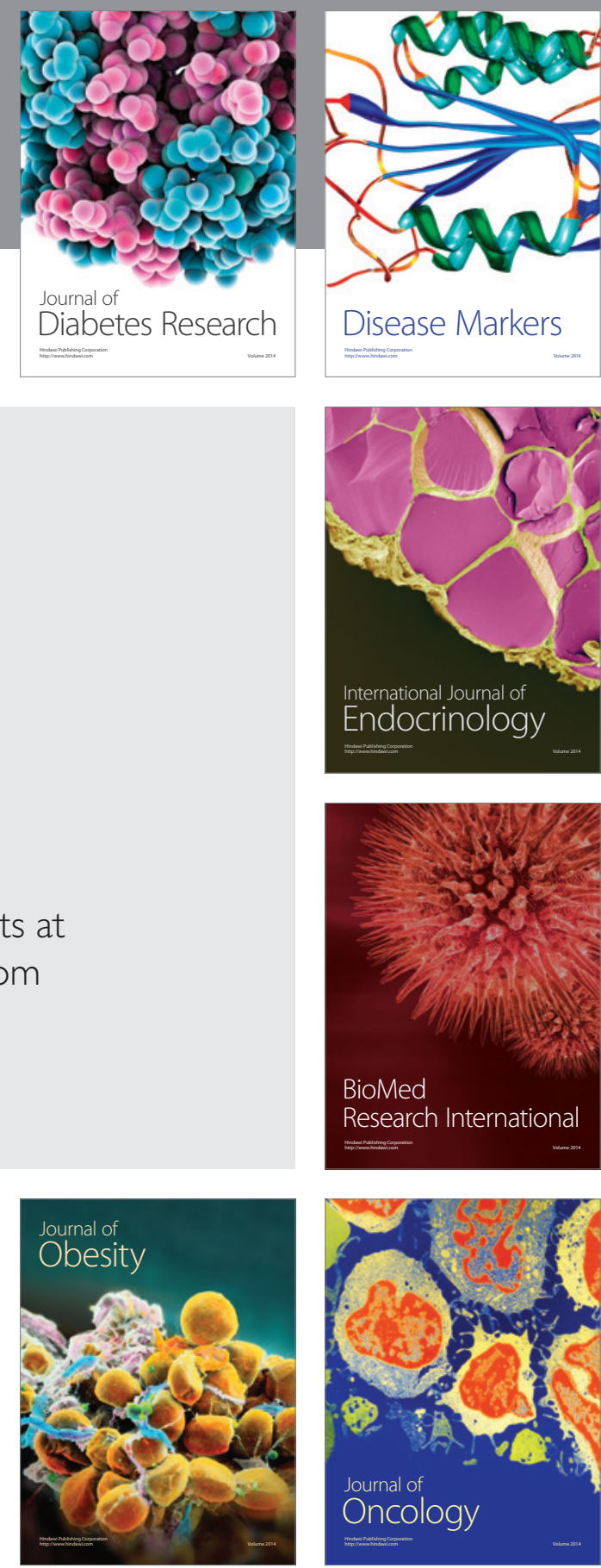

Disease Markers
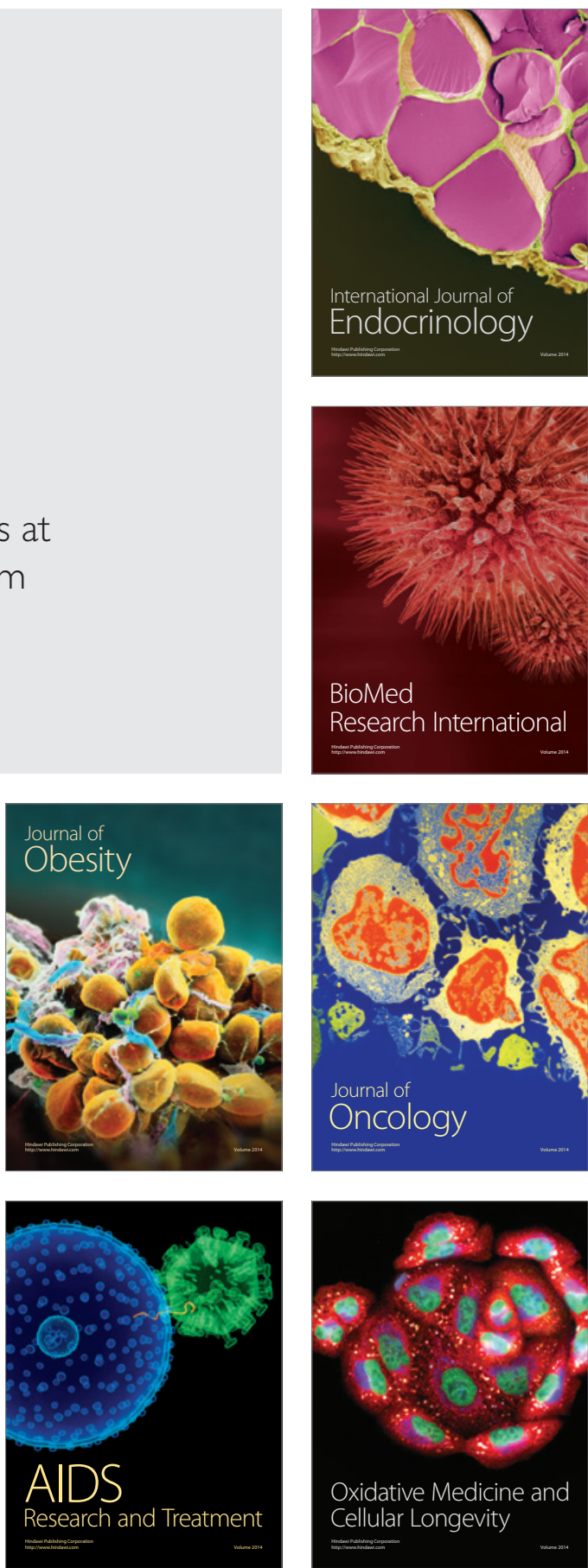